\title{
Attachment, Emotion Regulation and Coping in Portuguese Emerging Adults: a Test of a Mediation Hypothesis
}

\author{
Joana Cabral ${ }^{1}$, Paula M. Matos ${ }^{1}$, Wim Beyers ${ }^{2}$, and Bart Soenens ${ }^{2}$ \\ ${ }^{1}$ Universidade do Porto (Portugal) \\ ${ }^{2}$ University of Gent (Belgium)
}

\begin{abstract}
Although the quality of parent-adolescent emotional bonds has consistently been proposed as a major influence on young adult's psycho-emotional functioning, the precise means by which these bonds either facilitate or impede adaptive coping are not well-understood. In an effort to advance this inquiry, the present study examined interrelationships among measures of parental attachment, emotion regulation processes, and preferred coping strategies within a sample of 942 college freshmen. Structural Equation Modelling was used to test whether the link between attachment to parents and the use of particular coping strategies is mediated by differences in emotion regulation mechanisms. As hypothesized, differences in attachment to parents predicted differences in the use of emotion regulation mechanisms and coping strategies. More specifically, having a close emotional bond, feeling supported in autonomy processes and having (moderately) low levels of separation anxiety toward parents predict more constructive emotion regulation mechanisms and coping strategies. Additionally emotion regulation was found to (partly or totally) mediate the association between attachment and coping.

Keywords: attachment to parents, coping, emotion regulation, emerging adults, structural equations modelling.
\end{abstract}

Aunque la calidad de los lazos emocionales entre padres y adolescentes siempre ha sido propuesta como una importante influencia en el funcionamiento psico-emocional del adulto joven, los mecanismos precisos por los cuales estos lazos facilitan o impiden el afrontamiento adaptativo no son bien conocidos. En un esfuerzo por avanzar en esta indagación, el presente estudio examinó las interrelaciones entre las medidas de apego parental, los procesos de regulación emocional, y las estrategias preferidas de afrontamiento en una muestra de 942 estudiantes de primer año de universidad. Para probar si la relación entre el apego a los padres y el uso de determinadas estrategias de afrontamiento está mediada por las diferencias en los mecanismos de regulación emocional, se utilizaran Modelos de Ecuaciones Estructurales. Como fue hipotetizado, las diferencias en el apego a los progenitores se demostraron predictivas de diferencias en el uso de los mecanismos de regulación emocional y estrategias de afrontamiento. Más específicamente, tener un vínculo afectivo cercano con los padres, sentir su apoyo en los procesos de autonomía y sentir niveles (moderadamente) bajos de ansiedad de separación hacia los progenitores, son condiciones predictivas de mecanismos de regulación emocional y estrategias de afrontamiento más constructivos. Además, se encontró en la regulación emocional un mediador (total o parcial) para la asociación entre el apego y el afrontamiento.

Palabras clave: apego a los padres, afrontamiento, regulación emocional, adultos emergentes, modelos de ecuaciones estructurales.

A Portuguese Foundation for Science and Technology (FCT) PhD. scholarship grant (SFRH/BD/18357/2004) was attributed to the first author. This study has also been supported by the FCT research grant PTDC/PSI/65416/2006.

We would like to acknowledge Prof. Frederick Lopez greatly appreciated collaboration on the revision of and feedback on this manuscript.

Corresponding concerning this article should be addressed to Joana Cabral. E-mail: cabral.jo@gmail.com 
Beginning in adolescence and throughout emerging adulthood (Arnett, 2000, 2004) relationships with parents are reorganized, a process which co-occurs with changes in the hierarchy of attachment relationships (Allen \& Land, 1999, Bowlby, 1978). Peers, including romantic ones become increasingly relevant sources of support (Furman \& Buhrmester, 1992). However, building upon the notion of internal working models of early attachment experiences (Bowlby, 1978), the influence of parental attachment is generally acknowledged as an ongoing influence on individual development throughout the life span. More specifically, internalized representations of parental attachments are presumed to impact how situations are cognitively represented, as well as organizing features of self and, consequently, psycho-emotional functioning. Moreover, the change in the hierarchy of attachment does not mean that parents are disregarded as sources of support, especially in transition times. Transition and adaptation to college represents a source of important developmental and adjustment challenges for emerging adults. Given the nature of the challenges involved in adjustment to college tasks, as can be examples the reorganisation of study habits and the engagement on more interdependent and intimate relationships with peers, internal working models of self and others may be consulted and revised (Kenny, 1987. Moreover, being an experience of discontinuity, experiences of vulnerability may occur at a higher or lower intensity, therefore activating the attachment system (e.g. Rice, FitzGerald, Whaley, \& Gibbs, 1995). This attachment system activation results in a need for comfort and security provided by attachment figures. Empirical findings show that college students levels of psycho-emotional distress and adjustment to college vary as a function of the quality of their attachment with parents, as well as of the coping strategies employed (e.g., Bernier, Larose, Boivin, \& Soucy, 2004; Lopez, Maurício, Gormley, Simko, \& Berger, 2001; Vivona, 2000). The maintenance of closeness with parents emerges as another widespread finding. Parents not only remain as important resources of support, as well as seem to foster autonomization, developmental and adjustment processes (Lapsley \& Edergton, 2002; Rice et al., 1995).

Parental attachment is, hence, argued as an enduring crucial resource for late adolescents and emerging adults (McCarthy, Moller, \& Fouladi, 2001. With adolescents gaining autonomy, relationships with parents become, however, more reciprocal (Rice, FitzGerald, Whaley, \& Gibbs, 1995). This is, nevertheless a synergistic process. The closeness-autonomy balance reflects the presence of a secure base (Allen et al., 2003), involving both the maintenance of a sense of closeness and support, as well as autonomy encouragement (Grotevant, 1998; Lapsley \& Edergton, 2002).

This study intends to extend on empirical evidences regarding the importance of parental attachment for the quality of emotion regulation processes and coping strategies. The influence of specific features of these relationships, such as emotional closeness, separation anxiety and autonomy encouragement, will also be explored. Moreover, a processual approach is privileged, with the mediating role of emotion regulation processes being inspected in what regards the link between attachment and coping.

\section{Attachment and coping}

The link between attachment and coping can be considered theoretically well grounded. Coping responses are proposed to be influenced by a sense of personal security to deal with adversities, perceptions of selfcompetence, and perceptions of the usefulness of others as resources when facing personal distress (Kobak \& Sceery, 1988; Lopez \& Brennan, 2000; Mikulincer, Shaver, \& Pereg, 2003; Seiffge-Krenke, \& Beyers, 2005). These personal perceptions are embedded in the representations of self and others and built upon the history of interactions with attachment figures (Bowlby, 1978, 1988).

Studies exploring links between attachment and coping have consistently found that variability in quality of attachment relationships is related to variability in the strategies employed when facing stressful situations, as well as in the perception of the situation as threatening and demanding. These interpersonal variations have been attributed to differences in appraisals of self-competence, external resources, including support from others. Persons reporting more secure attachment relationships tend to evidence higher perceptions of social competency and selfefficacy, more optimistic expectancies and perceptions of controllability (Mikulincer \& Florian, 1998), more positive and constructive appraisals, and are more likely to appraise stressful situations as challenges than as threats (Fuendeling, 1998; Greenberger \& McLaughlin, 1998). These self and situational appraisals favour the use of coping approaches that privilege seeking support and that evidence active, systematic, and intentional coping strategies, characterized by planning, reflecting upon, and anticipating the consequences of one's actions (Greenberger \& McLaughlin, 1998; Lopez et al., 2001). Insecure attachment patterns, on the other hand, more frequently, tend to privilege less constructive coping approaches, showing, in general a lower engagement in active and approaching coping, less effective use of social support, and greater use of avoidant and/or suppressive coping strategies (Harvey \& Byrd, 2000; Ognibene \& Collins, 1998; Lopez et al., 2001). Once again, these privileged coping approaches are linked to self and other internal representations. Namely, self-perceptions of inefficacy and social incompetence; pessimistic expectations (Mikulincer \& Florian, 1998; Ognibene \& Collins, 1998); exacerbated appraisals of threat; perceptions of situations as irreversible and/or uncontrollable; and self-depreciative explanatory styles (Fuendeling, 1998; Greenberger \& 
McLaughlin, 1998). The anxious and/or avoidant attachment experiences also seem to influence the personal perceptions of coping ability with consequences for psychosocial distress (Wei, Heppener, Mallinkcrodt, \& 2003).

Although theoretically there are enough arguments supporting the link between attachment, dimensionally approached, and coping (Fuendeling, 1998; Mikulincer et al., 2003), most research findings result from studies with a categorical approach, as reflected by the previous review. This study is an attempt to understand the influence of attachment on coping strategies from a dimensional stance. It seems reasonable to argue that, coping being an ensemble of processes elicited by a stressful encounter or a threat, representations of self and others (i.e., internal working models), along with the prevailing strategies used when facing activation of the attachment system, are key concepts in these processes. More specifically, we aim to understand how the closeness and supportive character of attachment relationships with parents (high perceived Quality of Emotional Bond), the experience of being encouraged to be autonomous and engage in exploratory behaviours (low levels Inhibition of Exploration and Individuality), along with manageable low levels of Separation Anxiety, may foster a sense of personal security to face stressful events and cope with them in a constructive manner, i.e., privileging active and reflexive coping strategies, seeking support, positive reframing the situation, as well as making a lower use of avoidant coping.

\section{Attachment and emotion regulation}

The attachment system is intrinsically linked with the regulation of emotions (Cassidy, 1994; Kobak \& Sceery, 1988). Early attachment interactions serve the purpose of alleviating distress and re-establishing a sense of internal security, by means of maintaining proximity with protective nurturing figures (Ainsworth, Blehar, Waters, \& Wall, 1986, Bowlby, 1979, 1988). This dyadic nature is acknowledged among theorists as promoting the development of emotion regulation (Campos, Frankel, \& Camras, 2004; Diamond \& Aspinwall, 2003; Gross, 1998; John \& Gross, 2007; Thompson, 1994) as well as perceptions of personal control (Chorpita \& Barlow, 1998). Emotional signals (e.g, crying and anger) work as manifestations of the attachment system activation and regulate the consequent caregiver-child interactions. Consistently available and attuned caregiver responsiveness promotes the development of "self-reflective" capabilities (Fonagy, Steele, Steele, Moran, \& Higgitt, 1991) also fostering the open experience/expression of a diversity of positive and negative emotions (Cassidy, 1994). On the other hand, experiences of non-responsiveness and rejection or caregiver's retraction from proximity when feelings of distress and vulnerability are displayed (Ainsworth et al., 1986) are likely to promote a "minimization" or inhibition of emotion information-processing and expression, which in turn, may dispose the individual toward adopting less effective coping strategies. Inconsistent or inefficient caregiving experiences are likely to result in a "heightened" emotionality (Main, 1990). Both the minimization (deactivation strategy) and heightening of emotions (hyperactivation strategy) have a strategic function, being the best adaptive response given the attuned character of attachment interactions (Main, 1996). This co-regulation mode is progressively internalized, with functions once performed by nurturing developing into self-regulating modes of dealing with distress and emotional vulnerabilities in later ages (Bowlby, 1979, 1988; Mikulincer, Shaver, \& Pereg, 2003). Cognitive-emotional self structures are therefore organized, including: a sense of personal security and competence in dealing with personal distress and adversities; perceptions of the usefulness of proximity seeking in alleviating distress; a predominantly anxious or avoidant subjective experience once the attachment system is activated; and specific strategies to manage perceived threats to the sense of personal security. These cognitive-emotional structures are on the basis of stylistic configurations (Fuendeling, 1998) or personal styles (Cassidy, 1994) of emotion regulation in later ages, having been influenced by early experiences (Chorpita \& Barlow, 1998; Sroufe, 2005) and by the repeated activation of specific neural circuits, excitatory or inhibitory (in the case of hyperactivation or deactivation, respectively; Shaver \& Mikulincer, 2002).

The present study focuses on the influence of the quality of parental attachment on constructive emotion regulation approaches, which will contribute to the maintenance of a sense of "felt security" (Sroufe \& Waters, 1977). More specifically in the way the secure base and safe haven experiences, reflected by the (higher) Quality of the Emotional Bond, (lower) Inhibition of Exploration and Individuality and Separation Anxiety, result in higher levels of Clarity and Regulation and lower of Suppression, Difficulties in Defensive Repression, and Brooding.

Finally it is important to make a clear distinction between emotion regulation and coping processes. It is common to find references to emotion regulation as a feature of coping and vice-versa. Though many times referred as interchangeable, the distinct nature of these processes calls for some conceptual clarifications. Emotion regulation is here conceptualized as the ongoing process of activation and emotional arousal, modulation and management of attention direct to this arousal, cognitive processes of giving meaning to emotions, and efforts to modulate emotional effects of emotion experience on cognitive and affective experience (Gross \& Thomson, 2007; Fuendeling, 1998); whilst coping represents any response, strategy, effort or attempt to deal with a stressful situation, seen as exceeding the personal resources, being it internal, external or both (Lazarus \& Folkman, 1984). Although emotion arousal and interpretation are inevitably involved in coping processes, these emotional experiences and their regulation are concomitant and not the same as coping (Gross \& Thomson, 
2007). Emotion regulation occurs even in the absence of a stressful situation or problem, in relational interactions, as a response to good news or positive achievement. Emotion regulation deals with emotional experiences of any kind on a daily basis, in other words, every time emotional states are activated, which is not limited to stressful situations and problems. Coping, on the other hand, goes beyond emotional "actions" (Gross, 1998).

It is important to note that most studies mentioned (e.g., Lapsley \& Edergton, 2002; Lopez et al., 2001; Rice et al., 1995; Vivona, 2000) above were based on college student samples and therefore are especially pertinent for the understanding of the cognitive and emotional dynamics linked with attachment for this specific group.

\section{Mediating processes}

Coping and emotion regulation can be understood as a merging binomial and are commonly approached as inherently interdependent processes either in attachment (Fuendeling, 1998; Lopez \& Brennan, 2000), coping (Folkman \& Moskowitz, 2004; Gohm \& Clore, 2002) and emotion regulation (Gross \& Thomson, 2007) frameworks. Furthermore, particular features of emotion regulation, by influencing intensity, cognitive organization and modulation of emotions direct, in turn, to preferred coping styles (Lazarus, 1993). Fuendeling (1998) additionally argues that "stylistic configurations" of emotion regulation mechanisms may have a mediational role on the attachment-coping link. Though support for both the link between attachment and coping, and the first and emotion regulation has been gathered, no studies specifically addressing the associations between all of the three variables were found. Moreover, the interdependence between emotion regulation and coping is usual theoretically assumed (e.g., Lazarus, 2003; Gross, 1998), yet less frequently empirically supported. As said before, empirical findings tend to focus on differences regarding emotion regulation and coping strategies, as a function of attachment patterns (Gentzler \& Kerns, 2006; Waters, Crowell, Elliot, Corcoran, \& Treboux, 2002). There is, hence, a lack of studies using indicators of the quality of attachment relationships. With few exceptions (e.g., Gentzler \& Kerns, 2006; Mikulincer et al., 2003), there is also a lack of studies that approach the subject from a process-focused stance, searching for the mechanisms that underlie these associations.

\section{Hypotheses}

As argued before, the mediating mechanisms by which parental attachment affects the deployment of coping strategies remains unclear. In an effort to address this gap, the present study explored the impact of the quality of attachment relationships with parents, assessed from a dimensional stance, on emotion regulation mechanisms and on coping processes in a sample of emerging adults.
In order to address the specific hypotheses of this study, it is necessary to advance that parental attachment was measured with the Father and Mother Attachment Questionnaire (FMAQ; Matos \& Costa, 2004), a theoretically driven instrument developed in Portugal and validated across independent studies. Like several other self-report measures of parent-adolescent attachment relationships (Parental Bonding Instrument, Parker, Tulping, \& Brown, 1979, the Parent and Peer Attachment Inventory, Armsden \& Greenberg, 1987, and the Parental Attachment Questionnaire, Kenny, 1990) this questionnaire yields continuous scores on three dimensions assumed to reflect core features of the quality of parental attachment relationships. The Quality of Emotional Bond dimension taps variability in the emerging adult's experience of emotional closeness with, and confidence in parents' role as support and security providers. The dimension of Inhibition of Exploration and Individuality reflects the degree to which parents are perceived as intrusive or, on the contrary, as encouraging the emerging adult's personal autonomy and independent exploration. Lastly, the dimension of Separation Anxiety assesses variability in the emerging adult's fears of parental loss or abandonment. The combination of these dimensions can be seen as a reflection of the core concept of secure base, which would mean having an emotionally close and supportive relationship with parents (i.e., high levels of Quality of Emotional Bond), perceiving them as encouraging of autonomy development (low levels of Inhibition of Exploration and Individuation) and feeling free from fears of loss and abandonment (low/manageable levels of Separation Anxiety).

In what concerns the hypotheses, it is expected that the Quality of Emotional Bond (QEB) positively predicts Active/Reflexive, Seeking Support, and Positive Reframing, and negatively the use of Avoidant Coping. The opposite direction of predictions is expected for Inhibition of Exploration and Individuality (IEI) and Separation Anxiety (SA). It is also expected that the Quality of Emotional Bond (QEB) positively predicts Clarity and Regulation and negatively Difficulties in Defensive Repression and Rumination (Brooding). IEI and SA are expected to positively predict the latter and negatively predict adaptive emotion regulation (Clarity and Regulation). Additionally, more constructive emotion regulation dynamics are expected, in turn, to predict equally constructive coping approaches, in sum, mediating the association between attachment and coping.

Method

\section{Participants}

The sample includes 942 white and Caucasian freshmen from various courses in the University of Porto - 344 men (36.5\%) and 598 women (63.5\%), with ages ranging from 
17 to $20(M=17.95 ; S D=.54)$. A considerable percentage of students live away from their homes $(389 ; 41.3 \%)$, in a rented room or apartment (alone, with relatives, with friends or colleagues), or in residence halls, during school period, and most $(324 ; 34.4 \%)$ return to their homes every weekend. Regarding education levels, the majority of parents have a Higher Education degree (271, 28.9\% and 304, 32.3\%, in the case of father and mother respectively). This sample results from previous diagnosis of outliers, using various methods (ZScores, Mahalanobis Distances, Cook's and DFBetas values). Decisions concerning their deletion or maintenance were made based on this information, as well as on the consistent nature of responses patterns.

\section{Procedure}

Data collections were conducted during classes during the first weeks of their freshmen year. Participants were, hence, recruited by convenience and assuring their voluntary intention to participate (they could choose not to respond to the package of questionnaires). No incentive was used. Students were asked to participate in a study concerning the psychosocial development of college students, being the main goals of this study briefly presented. The voluntary nature of their participation, along with the confidential nature of the responses and collected data were pointed out.

\section{Measures}

With the exception of FMAQ, all the questionnaires were translated to Portuguese according to the guidelines of the International Test Commission (Hambleton, 2005). All measures were also tested for their dimensional structure, construct validity and internal consistency using Exploratory (PCA) and Confirmatory Factor Analysis (CFA) procedures. FMAQ and RRS original structures were maintained, while alternative structures were found for COPE and TMMS measures that are in agreement with current theoretical advancement in the field and recent empirical studies.

Father and Mother Attachment Questionnaire (FMAQ; Matos \& Costa, 2004). Assesses attachment with each parent along 3 main dimensions: Inhibition of Exploration and Individuality (e.g., "My parents discourage me when I want to try new things."); Quality of Emotional Bond (e.g., "I know that I can count on my parents whenever I need them"); Separation Anxiety (e.g. "I am afraid of being alone if I lose my parents."). Cronbach's alpha for the present sample varies between .85 and .93 for the mother relationship, and between .86 and .89 for the father relationship. Evidence of construct validity was gathered by associations found in the expected direction with other attachment measures, such as the Inventory of Parent and Peer Attachment (Armsden \& Greenberg, 1987), and the
Family Environment Scale (Moos \& Moos, 1986), as well as with other measures of theoretically relevant constructs (Gouveia \& Matos, 2011; Matos \& Costa, 2004).

COPE Inventory (Carver, Scheier, \& Weintraub, 1989). After the exploratory and confirmatory factor analyses previously conducted, a scale structure including 4 dimensions was adopted. The 4 dimensions reflect: Active/Reflexive (e.g., "I take direct action to get around the problem"; "I try to come up with a strategy about what to do."), Seeking Support (e.g., "I discuss my feelings with someone."), Avoidant (e.g., "I pretend that the situation didn't really happen."), and Positive Reframing strategies (e.g., "I think about other things besides the situation/problem."; "I try to see it in a different light and more positive way."). Cronbach's alpha values range from .78 to .80 , with the exception of the Positive Reframing dimension (5 items), which showed an alpha of .66. The found structure is consistent with other studies that reported high interscale correlations and suggested second-order factors (e.g., Carver et al., 1989; Clark, Bormann, Cropanzano, \& James, 1995; Lyne \& Roger, 2000; Kallasmaa \&, Pulver, 2000; Litman, 2006).

Trait Meta-Mood Scale (TMMS; Salovey, Mayer, Goldman, Turvey, \& Palfai, 1995). Again, following exploratory and confirmatory factor analyses, a final structure with 4 dimensions was found, including: Suppression (e.g., "Feelings are a weakness humans have"), Clarity (e.g., "I am rarely confused about how I feel."), Regulation (e.g., "No matter how bad I feel, I try to think about pleasant things."), and Difficulties in Defensive Repression (DDR) (e.g., "When I feel down I can't avoid negative feelings."). This structure is theoretically consistent and especially interesting regarding the emotion regulation dynamics usually associated with attachment (e.g., Fuendeling, 1998; Lopez \& Brennan, 2000; Mikulincer et al., 2003; Shaver \& Mikulincer, 2007). The version of the measure adopted in the present study shows adequate reliability, with alpha values between .68 to .85 .

Ruminative Responses Scale (RRS; Treynor, Gonzalez, $\&$ Nolen-Hoeksema, 2003). Only Brooding was used (e.g., "Think "I won't be able to concentrate if I keep feeling this way"). This dimension of rumination reveals high reliability $(\alpha=.89)$, even higher comparing to the one found in the original version ( $\alpha=.77$; Treynor et al., 2003). A 6 point scale (from totally disagree to completely agree) was equally adopted for all measures.

\section{Overview of analyses}

The analyses were conducted using Structural Equation Models (SEM; with EQS, 6.1 version) and following Baron and Kenny's (1986), (Kenny, 2006) four steps for testing mediational effects. Across each step modification indices (e.g. Lagrange Multiplier and Wald test) were used to maintain or drop paths. 

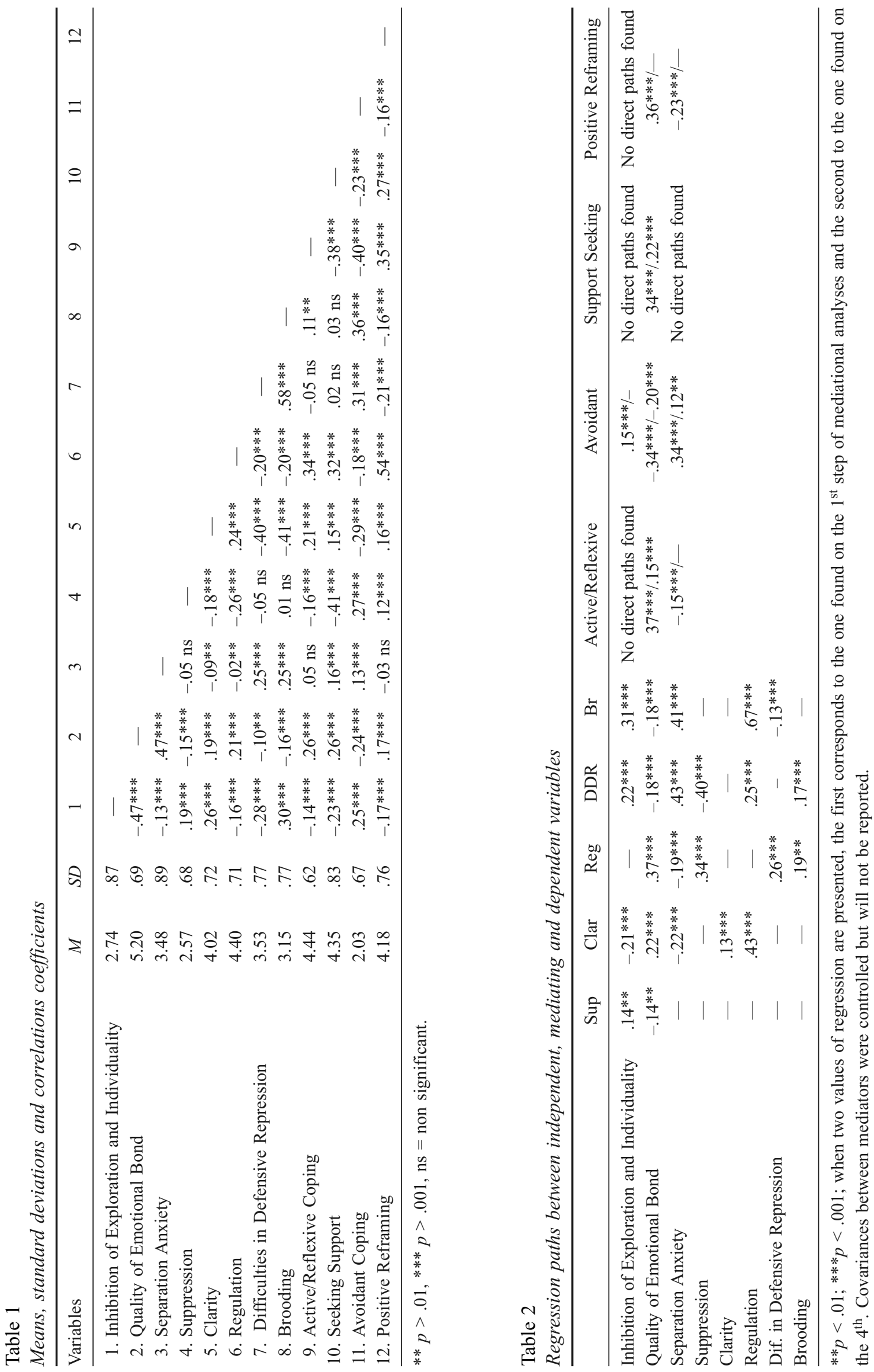
Based on results from preliminary analysis (MANCOVAs), used to test the influence of some sociodemographic variables (such as: gender, level of education and occupation of parents, as well as the living situation of the participant) on the variables in study were included and controlled for in all 4 steps of the analyses. Since these results lie outside the scope of the present paper, and also given space limitations, they will not be presented nor discussed.

Before beginning with the description of findings, some clarifications should be made. Total and partial mediation refer, respectively, to situations in which the links found in the $1^{\text {st }}$ step (when only independent and dependent variables were present) turned non significant or pronouncedly dropped in predictive power. All mediated paths are indirect effects, in a broad sense. Yet, the term indirect effect or link was here used in a more strict sense, referring to the paths between attachment and coping variables that only emerged in the presence of the intervening variables of emotion regulation (but not in the $1^{\text {st }}$ step). In this case there is no shared variance and no direct association between attachment and coping variables.

\section{Measurement Model}

In order to guarantee a simultaneously comprehensive and parsimonious model, some decisions were made. Considering that one unique global indicator of parental attachment could mask some particularities regarding the associations between each attachment dimension, emotion regulation and coping variables, a decision was made to use the 3 variables or dimensions tapping the quality of attachment relationship. Given the high correlation between father and mother separate scores on the IEI, QEB and SA dimensions (ranging between .72, $p .<.01$ for QEB, and .89, $p<.01$ for SA), which raised questions of multicolinearity and redundancy, each dimension was represented in the model as a latent variable combining both the father and mother scores as indicators. All four coping strategies were included as final dependent variables, along with the four dimensions of the TMMS and the Brooding dimension from RRS, as mediating ones. Since the purpose was to understand the preferred orientations towards each of the distinct coping strategies given the predictive role of attachment dimensions and the mediating role of each specific emotion regulation dynamic, using grouping or composite variables for coping and/or emotion regulation would result in a less analytic perspective, hindering the above-mentioned goal. Hence, the 4 coping strategies were included as separate variables in the model. Latent variables, using items parcels of items as observed variables, based on the previous Confirmatory Factor Analyses procedures, were used for all emotion regulation and coping dimensions (for details on the advantages and techniques for parcels see Little, Cunningham, Shahar \& Widaman, 2002) and. It is worth mentioning that the covariance among the 3 independent variables (attachment), as well as among the mediating (emotion regulation) and dependent ones (coping) was included in the model, in order to assure that their shared variance was controlled for and that the found effects were unique ones.

\section{Results}

\section{Descriptive statistics and correlation analysis}

As preliminary results, correlation analyses were performed with all the variables in study. These results are presented in table 1.

\section{Mediation analyses}

The results from the last model (or $4^{\text {th }}$ step of the mediation analyses) support mediation, as illustrated by table 2 below. The model shows good adjustment indices $\left(\chi_{(382)}^{2}=1214.315, p<.0001 ; \mathrm{CFI}=.94 ; \mathrm{SRMR}=.04 ;\right.$ and RMSEA $=.05$, IC $90 \%=.05-.07)$. Beginning with results regarding the Quality of Emotional Bond (QEB), total mediation was found between this dimension and Positive Reframing coping strategies. High levels of Regulation and low levels of Difficulties in Defensive Repression (DDR) mediate the association between (high) Quality of Emotional Bond and higher Positive Reframing. Partial mediated paths were found in the case of the three remaining coping strategies. The higher the level of QEB, the higher the levels of the Clarity and Regulation and, in turn, of Active/Reflexive coping. High levels of Regulation and low levels of Brooding mediate the link between QEB (high) and Support Seeking (also high). The link between QEB and Avoidant coping is mediated by DDR and Brooding. The higher the levels of QEB the lower the levels of these emotion regulation dimensions and, accordingly, the lower the engagement in avoidance. Along with these partially mediated paths, QEB remains as a direct and positive predictor of Seeking Support and Active/Reflexive coping strategies, as well as a negative and direct predictor of Avoidant ones.

For Inhibition of Exploration and Individuality (IEI) evidence supporting total mediation was found concerning the link with Avoidant strategies. The higher the levels of IEI the higher the use of Avoidant strategies, being this link totally mediated by high levels of Brooding, DDR and Suppression. Some indirect links, not present as direct links in the $1^{\text {st }}$ step model, can also be seen with the other three coping strategies. The higher the levels of IEI the lower the levels of Clarity and, in turn, the lower the use of Active/Reflexive coping. A higher use of Seeking Support is also indirectly predicted by high levels of IEI, by means of higher levels of Brooding; however high levels of IEI 
Table 3

Indirect effects and significance

\begin{tabular}{|c|c|c|c|c|c|c|c|c|c|c|c|c|}
\hline & \multicolumn{3}{|c|}{ Active/Reflexive } & \multicolumn{3}{|c|}{ Avoidant } & \multicolumn{3}{|c|}{ Support Seeking } & \multicolumn{3}{|c|}{ Positive Reframing } \\
\hline & $\begin{array}{c}\text { Stand. } \\
\text { Coef. }\end{array}$ & $S E$ & $Z$ & $\begin{array}{l}\text { Stand. } \\
\text { Coef. }\end{array}$ & $S E$ & $Z$ & $\begin{array}{l}\text { Stand. } \\
\text { Coef. }\end{array}$ & $S E$ & $Z$ & $\begin{array}{l}\text { Stand. } \\
\text { Coef. }\end{array}$ & $S E$ & $Z$ \\
\hline Inhibition of Exploration and Individuality & -.03 & .01 & $-2.951 * *$ & .16 & .02 & $6.470 * * *$ & -.001 & .02 & $-.045 \mathrm{~ns}$ & -.03 & .01 & $-2.972 * *$ \\
\hline Quality of Emotional Bond & .19 & .03 & $7.472 * * *$ & -.13 & .03 & $-4.964 * * *$ & .12 & .03 & $4.042 * * *$ & .274 & .04 & $8.236^{* * *}$ \\
\hline Separation Anxiety & -.11 & .02 & $-5.438 * * *$ & .19 & .03 & $7.961 * * *$ & .02 & .01 & $1.199 \mathrm{~ns}$ & -.03 & .01 & $-2.972 * *$ \\
\hline
\end{tabular}

$* * p<.01 ; * * * p>.001 ; \mathrm{ns}=$ non significant.

also indirectly predict lower engagement in Support Seeking, through higher levels of Suppression. Finally, high levels of IEI predict high levels of DDR which, in turn, lead to lower engagement in Positive Reframing.

In the case of Separation Anxiety (SA), only one direct path remains in the final model (step 4), indicating partial mediation. SA directly and positively predicts Avoidant coping strategies, even though the magnitude of the regression path is relatively weak. High levels of DDR and Brooding partially mediate this link between high SA and high engagement in avoidance. The two other direct paths found in the $1^{\text {st }}$ step, with Active/Reflexive and Positive Reframing strategies are totally mediated. High SA predicts low levels of both Clarity and Regulation and, consequently, low levels of Active/Reflexive strategies. High levels of DDR and low levels of Regulation totally mediate the association between high levels of SA and low levels of Positive Reframing. There are also indirect paths that were only found in this last model (step 4), revealing that high levels of SA differently predict a high and/or low use of Seeking Support strategies, as a function of the mediator. High levels of SA predict low levels of Regulation which, in turn, result in low support seeking, whereas, high levels of SA also predict high levels of Brooding that, in turn, are predicted of higher engagement in Seeking Support strategies.

Finally, $31.0 \%, 40.0 \%, 38.6 \%$ and $52.8 \%$ of the variance on Active/Reflexive, Avoidant, Support Seeking and Positive Reframing coping strategies, respectively, is explained by the attachment and emotion regulation variables.

\section{Indirect effects}

All mediated and indirect paths were found to be significant (see table 3), with the exception of the indirect links between Inhibition of Exploration and Individuality (IEI), Separation Anxiety (SA) and Support Seeking. In both cases the indirect links include two mediating or intervening variables with an opposite pattern of association (Suppression and Brooding for IEI and Regulation and Brooding for SA). The possibility that the mediators were having a suppressing effect on each other was explored dropping the link between the IEI and SA and one of the two intervening variables while maintaining the other. When the link between IEI and Suppression was dropped, the indirect effect of IEI on Support Seeking, carried out by Brooding, became significant (Stand. Coef. $=.05 ; \mathrm{SE}=$ $.01 ; Z=3.922$ ). The same happened when the link between IEI and Brooding was dropped (Stand. Coef. $=-.06$; $\mathrm{SE}=$ $.01 ; Z=-3.419)$. Repeating these procedures in the case of SA, first the link with Regulation was dropped and then the one with Brooding. Again the indirect effect carried out by Brooding (Stand. Coef. $=.07 ; \mathrm{SE}=.01 ; \mathrm{Z}=4.344$ ) and Regulation (Stand. Coef. $=-.03 ; \mathrm{SE}=.01 ; Z=-3.120$ ), respectively, was found to be significant. These findings suggest a suppressing effect resulting from the opposite pattern of association between the independent and dependent variables as a function of the nature of the intervening variable. Chi-square differences between the global model and the nested models with parameters dropped (global model shows a lower chi-square comparing with all other models) were calculated and found to be significantly higher comparing to the critical value, suggesting that the parameters were to be maintained (Steiger, Shapiro, \& Browne, 1985).

\section{Discussion}

Theory and research have been stressing the prospective and transversal influence that the history of attachment experiences has on psycho-emotional functioning and adjustment in various areas (Lopez \& Brennan, 2000). The aim of this study was to examine the processes underlying the influence of attachment on psycho-emotional functioning. More specifically, to gather support for the assumption that the distinct quality of attachment relationships with parents influences the constructive character of coping responses and, moreover, that emotion regulation mechanisms have a mediating role on the attachment-coping link.

As expected the Quality of Emotional Bond (QEB) is predictive of more constructive coping, as well as emotion regulation processes, being one of the strongest predictors of these processes. QEB is also one of the variables with more links with both coping and emotion regulation 
variables in the models. The opposite pattern of results was found for Separation Anxiety (SA) and Inhibition of Exploration and Individuality (IEI), which show a negative impact on coping strategies and emotion regulation mechanisms. Similarly to QEB, SA is also an important predictor of emotion regulation and coping mechanisms, showing comparably more and stronger links with these variables, especially when compared with IEI. The latter attachment dimension shows less links - only predicting Avoidant coping in the first step and three from the five emotion regulation dimensions - and an overall weaker predictive power. This may reflect the more structural character of QEB and SA as core markers of attachment, whilst IEI may be a more relational aspect of parental relationships, as later discussed.

Support for total and partial mediation was gathered. The link between Quality of Emotional Bond (QEB) and more constructive coping processes is partially mediated by equally more adaptive emotion regulation processes, and the link between QEB and Positive Reframing coping strategies is totally mediated. The remaining three direct paths underscore the structural importance of this relationship feature. It is worth mentioning that these remaining direct paths involve coping strategies that can be seen as more close to internal working models of self (e.g., Active/Reflexive and Avoidant), and others (Seeking Support) (Ognibene \& Collins, 1998), as well as internalized features of attachment experiences (e.g., attachment strategies). Consistent with previous research, having an emotional close and confident relationship with parents and feeling this relationship as a source of support and comfort, seems to be a learning context for emotion regulation and coping processes (Contreras, Kerns, Weimer, Gentzler, \& Tomich, 2000; Wei, Vogel, Tsun-Yao Ku, \& Zakalik, 2005). Although the measure used asked participants to report on their present relationships, current attachment relationships are argue to be influenced, at some extent, by past and early interactions (Shaver \& Mikulincer, 2002; Sroufe, 2005). Some of the QEB items are especially illustrative of these mixed past recalls and present perceptions (e.g., "I trust my parents to support me through difficult times in my life."; "I know I can rely on my parents anytime I need them."; "My parents have an important role on my development.").

Although to a lower extent, if compared with QEB, Separation Anxiety (SA) also seems to be a somewhat structural feature of attachment relationships, as well as related internalizations, having therefore a more general and pronounced influence on coping responses (the magnitude of indirect effects, greater for QEB and SA comparing with IEI, may also support this assumption; see table 3). The fact that the link with Seeking Support only emerged as an indirect effect may not mean, however, that this effect is not related to the influence of SA on internal working models and/or attachment strategies. The probable curvilinear character of SA along with the, consequently, nonlinear association with emotion regulation and coping processes points to the need to look beyond linear perspectives. SA predicts high Seeking Support as a coping strategy, but the mediated paths are qualitatively different, depending on the mediator. Lower levels of SA are predictive of higher Seeking Support, when mediated by higher levels of Regulation. Higher levels of SA are, however, also predictive of higher use of these same strategies, when higher levels of Brooding mediate the link. This non-linear association with coping could explain why the direct link did not emerge on the $1^{\text {st }}$ step.

The emotion regulation dimensions seem to totally account for the influence of Inhibition of Exploration and Individuality (IEI) on all coping strategies (there is one case of total mediation, while others are indirect effects). One possible interpretation for these results may rely on the somewhat more dynamic and relational nature of this dimension, whereas QEB and SA seem to have more structural influences, being more embedded in internalized features of personality and representations of self and others. More specifically, given that late adolescence is recognized as a period for reorganizing the balance between attachment and autonomy in relationships with parents (Arnett, 2000; 2004; Allen \& Land, 1999), this could mean that emerging adults may differ in the way they deal with the intrusive parenting and/or lack of autonomy encouragement from their parents, something that has been supported by other previous studies (Allen \& Hauser, 1996). The distinct ways in which emerging adults deal with intrusive and inhibiting parental practices (high IEI) may have accordingly distinct impacts on their more or less adaptive way of regulating emotions and, therefore, consequences for how they deal with threatening and disruptive situations may also differ (Lapsley \& Edergton, 2002; Noom, Dekovic, \& Meeus, 1999).

The discussed findings, supporting the mediation hypothesis, stress the central role of emotion regulation dynamics as intervening processes on psycho-emotional functioning and on the influence carried by attachment on adjustment responses, more specifically on coping approaches.

\section{Implications for practice}

This study was conducted with a sample of emerging adults' college students, thereby some directions for practice in this specific setting are in line. As seen, the experience of a secure base and safe haven in relationships with parents is of high potential for quality of emotion regulation processes, as well as, coping responses. These are crucial resources in face of transitions and adjustments, such as those implied in adjustment to college. Therefore counsellors and other elements with responsibility on the college experience should address these issues, planning activities that foster the maintenance of proximity with parents, along 
with autonomy development. Counselling activities with students should address issues related with homesickness, in the case of students living away from home, reorganization of relationships with parents, negotiation of autonomy and independence and maintenance of proximity with parents. Moreover counselling should help students to integrate and reorganize their (negative) memories of attachment experiences with parents, along with the emotions related with these memories.

\section{Limitations and implications for further research}

The use of various emotion regulation variables, although resulting in a somewhat complex model, seems to have the advantage of shedding light on the similarly complex interrelations between attachment and the cognitive-emotional dynamics of emotion regulation and coping, as well as on the mechanisms underlying the influence of attachment on psychosocial functioning and adjustment. Nevertheless, this assumption needs to be further explored by further studies also including other adjustment indicators.

A dimensional approach to attachment assessment was privileged, being thought to better fit the intended processual approach adopted. Nevertheless, and without compromising this processual approach, the understanding of some more refined individual differences could benefit from looking to attachment patterns and their particular organizational features. Seeking support is a particularly illustrative example of the potential differences as a function of the prevailing attachment strategy associated with distinct attachment organizations or patterns. High engagement in seeking support as a coping strategy is predicted by distinct mediated paths. These differences suggest that the specific meaning of the use of others as sources of support might also vary as a function of the previous internal and emotional experience, serving somewhat distinct purposes (Harvey \& Byrd, 2000; Lopez, 1996; Ogibene \& Collins, 1998). More specifically, it could be reasoned that individuals with a secure attachment pattern, characterized by experiencing emotionally supportive relationships with their parents (high QEB) - which contribute to a positive representation of others and to a perception of proximity seeking as helpful - and having a moderately low level of separation anxiety, are especially skilled at balancing and/or managing the use of others as a function of their needs. Individuals with a preoccupied attachment pattern, who tend to experience particularly high and disruptive levels of separation anxiety and to undertake hyperactivation strategies, on the other hand, are prone to be overwhelmed by a spiral spread of negative emotions (rumination), be dependent on and needing others as external sources to alleviate personal distress (Shaver \& Mikulincer, 2002). In sum, coping strategies can be seen as an extension of an internal emotional experience of threat, with distinct intensities, to the sense of personal security, resulting in a more or less pronounced experience of vulnerability, activating therefore the attachment system. This activation can, in turn, trigger the attachment strategies that vary between patterns (Shaver \& Mikulincer, 2002; Main, 1990; Mikulincer et al., 2003). We argue that incorporating attachment patterns in further extensions of these analyses, without loosing track of representations of the quality of the attachment relationships, could help to clarify this picture. For this purpose procedures such as latent class analyses and/or multigroup comparisons, could be used to test this model across groups of participants identified, as secure, preoccupied, fearful and dismissing - following Bartholomew and Horowitz (1991) empirically supported distinct styles - based clustering procedures with the three attachment dimensions (IEI, QEB, SA).

The more or less broad or specific nature of the emotion regulation dimensions used could be considered as a limitation. Whereas Clarity and Suppression are broadly related to general emotions and affects, Regulation, DDR and Brooding seem to mainly evoke particular kinds of emotions (sadness, feeling down or worried). This could weaken or even veil the paths to coping strategies not specifically related to these emotional experiences, and could explain why, contrary to what was expected, Clarity does not show significant paths to Avoidance and Positive Reframing strategies.

Like any other studies using self-report measures these results have some limitations given the responses' spontaneous nature and reliability. Responses may be biased by social desirability and defensive processes. The latter is a particularly pertinent issue considering that those with a pronounced attachment avoidance and deactivation strategy (characteristics of the dismissing attachment pattern) tend to describe idealized pictures of their parents and of their relationships, devalue distress and difficulties (Kobak \& Sceery, 1988; Mikulincer \& Florian, 1998) as a reflection of what Bowlby $(1978,1988)$ described as a compulsive self-reliance.

Finally, the cross-sectional nature of the data does not allow definitive assumptions regarding the causal direction of associations between the variables. Although the direction of the relationships were theoretically grounded, it is also possible to consider alternative directions and even mediation paths. Namely, given the interdependent nature of emotion regulation and coping, it would be pertinent to inspect if coping is predictive of the following quality of emotion regulation processes (for example, if Seeking support enhances Clarity and Regulation, or if Positive Reframing would predict lower levels of DDR, Brooding, as well as high levels of Regulation). Longitudinal data on emotion regulation and coping would allow taking this interdependence into account regarding the dynamic associations between attachment, emotion regulation and coping. 


\section{References}

Ainsworth, M. D. S., Blehar, M. C., Waters, E., \& Wall, S. (1986). Patterns of attachment: A psychological study of the strange situation. Hillsdale, NJ: Lawrence Erlbaum Associates.

Allen, J. P., \& Hauser, S. T. (1996). Autonomy and relatedness in adolescent-family interactions as predictors of young adults' states of mind regarding attachment. Development and Psychopathology, 8, 793-809. http://dx.doi.org/10.1017/ S0954579400007434

Allen, J. P., \& Land, D. (1999). Attachment in adolescence. In J. Cassidy \& P. R. Shaver (Eds.), Handbook of attachment: Theory, research, and clinical applications (pp. 319-335). New York, NY: Guilford Press.

Allen, J. P., McElhaney, K. B., Land, D. J., Kuperminc, G. P., Moore, C. W., O’Beirne-Kelly, H., \& Kilmer, S. L. (2003). A secure base in adolescence: Markers of attachment security in the mother-adolescent relationship. Child Development, 74, 292-307. http://dx.doi.org/10.1111/1467-8624.t01-1-00536

Armsden, G. C., \& Greenberg, M. T. (1987). The inventory of parent and peer attachment: Individual differences and their relationship to psychological well-being in adolescence. Journal of Youth and Adolescence, 16, 427-454. http://dx.doi. org/10.1007/BF02202939

Arnett, J. J. (2000). Emerging adulthood: A theory of development from the late teens through the twenties. American Psychologist, 55, 469-480. http://dx.doi.org/10.1037/0003066X.55.5.469

Arnett, J. J. (2004). Emerging adulthood: The winding road from the late teens through the twenties. New York, NY: Oxford University Press.

Baron, R. M., \& Kenny, D. A. (1986). The moderator-mediator variable distinction in social psychological research: Conceptual, strategic and statistical considerations. Journal of Personality and Social Psychology, 51, 1173-1182. http://dx.doi.org/10.1037//0022-3514.51.6.1173

Bartholomew, K., \& Horowitz, L. M. (1991). Attachment styles among young adults: A test of a four-category model. Journal of Personality and Social Psychology, 61, 226-244. http://dx. doi.org/10.1037//0022-3514.61.2.226

Bernier, A., Larose, S., Boivin, S., \& Soucy, N. (2004). Attachment state of mind: Implications for adjustment to college. Journal of Adolescent Research, 19, 783-806. http://dx.doi.org/10.1177/ 0743558403260096

Bowlby, J. (1978). Attachment and loss, Vol.1: Attachment. New York, NY: Basic Books.

Bowlby, J. (1988). A secure base: Parent-child attachment and healthy human development. London, England: Basic Books.

Campos, J. J., Frankel, C. B., \& Camras, L. (2004). On the nature of emotion regulation. Child Development, 75, 377-394. http://dx.doi.org/10.1111/j.1467-8624.2004.00681.x

Carver, C. S., Scheier, M. F, \& Kumari Weintraub, J. (1989). Assessing coping strategies: A theoretically based approach. Journal of Personality and Social Psychology, 56, 267-283. http://dx.doi.org/10.1037//0022-3514.56.2.267
Cassidy, J. (1994). Emotion regulation: Influences of attachment relationships. Monographs of the Society for Research in Child Development, 59, 228-249. http://dx.doi.org/10.2307/1166148

Chorpita, B. F., \& Barlow, D. H. (1998). The development of anxiety: The role of control in the early environment. Psychological Bulletin, 124, 3-21. http://dx.doi.org/10.1037//0033-2909.124.1.3

Clark, K. K., Bormann, C. A., Cropanzano, R. S., \& James, K. (1995). Validation evidence for three coping measures. Journal of Personality Assessment, 65, 434-455. http://dx.doi.org/10. 1207/s15327752jpa6503_5

Contreras, J. M., Kerns, K. A., Weimer, B. L., Gentzler, A. L., \& Tomich, P. L. (2000). Emotion regulation as a mediator of associations between mother-child attachment and peer relationships in middle childhood. Journal of Family Psychology, 14, 111-124. http://dx.doi.org/10.1037//0893-3200.14.1.111

Diamond, L. M., \& Aspinwall, L. G. (2003). Emotion regulation across the life span: An integrative perspective emphasizing self-regulation, positive affect, and dyadic processes. Motivation and Emotion, 27, 125-156. http://dx.doi.org/10.1023 /A: 1024521920068

Folkman, S., \& Moskowitz, J. T. (2004). Coping: Pitfalls and promise. Annual Review of Psychology, 55, 745-774. http://dx.doi.org/10.1146/annurev.psych.55.090902.141456

Fonagy, P., Steele, M., Steele, H., Moran, G. S., \& Higgitt, A. C. (1991). The capacity for understanding mental states: The reflective self in parent and child and its significance for security of attachment. Infant Mental Health Journal, 12, 201-218. http://dx.doi.org/10.1002/1097-0355(199123)12:3<201::AIDIMHJ2280120307>3.0.CO;2-7

Fuendeling, J. M. (1998). Affect regulation as a stylistic process within adult attachment. Journal of Social and Personal Relationships, 15, 291-322. http://dx.doi.org/10.1177/0265 407598153001

Furman, W., \& Buhrmester, D. (1992). Age and sex differences in perceptions of networks of personal relationships. Child Development, 63, 103-115. http://dx.doi.org/10.2307/1130905

Gentzler, A. L., \& Kerns, K. A. (2006). Adult attachment and memory of emotional reactions to negative and positive events. Cognition \& Emotion, 20, 20-42. http://dx.doi.org/10. 1080/02699930500200407

Gohm, C. L., \& Clore, G. L. (2002). Four latent traits of emotional experience and their involvement in well-being, coping, and attributional style. Cognition and Emotion, 16, 495-518. http://dx.doi.org/10.1080/02699930143000374

Greenberger, E., \& McLaughlin, S. C. (1998). Attachment, coping, and explanatory style in late adolescence. Journal of Youth and Adolescence, 27, 121-139. http://dx.doi.org/10.1023/ A: 1021607627971

Gross, J. J. (1998). The emerging field of emotion regulation: An integrative review. Review of General Psychology, 2, 271299. http://dx.doi.org/10.1037//1089-2680.2.3.271

Gross, J. J., \& Thompson, R. A. (2007). Emotion regulation: Conceptual foundations. In J. J. Gross (Ed.), Handbook of emotion regulation (pp. 3-26). New York, NY: The Guilford Press. 
Grotevant, H. D. (1998). Adolescent development in family contexts. In W. Damon \& N. Eisenberg, (Eds.), Handbook of child psychology (5 $5^{\text {th }}$ Ed.), Vol 3, Social, emotional, and personality development (pp. 1097-1149). New York, NY: John Wiley \& Sons Inc.

Gouveia, T., \& Matos, P. M. (2011). Manual QVPM: Questionário de Vinculação ao Pai e à Mãe [QVPM manual - attachment to mother and father questionnaire]. Retrieved from https://sites. google.com/site/manualqvpm/

Hambleton, R. K. (2005). Issues, designs, and technical guidelines for adapting tests into multiple languages and cultures. In R. K. Hambleton, P. F. Merenda, \& C. D. Spielberger (Eds.), Adapting educational and psychological tests for cross-cultural assessment (pp.3-38). Mahwah, NJ: Erlbaum.

Harvey, M., \& Byrd, M. (2000). Relationship between adolescents' attachment styles and family functioning. Adolescence, 35 , 345-356.

Hoffman, J. A. (1984). Psychological separation of late adolescents from their parents. Journal of Counseling Psychology, 31, 170-178. http://dx.doi.org/10.1037//0022-0167.31.2.170

John, O. P., \& Gross, J. J. (2007). Individual differences in emotion regulation. In J. J. Gross (Ed.), Handbook of emotion regulation (pp. 351-372). New York, NY: The Guilford Press.

Kenny, D. A. (2006). Mediation. Retrieved from http://davida kenny.net/cm/mediate.htm.

Kenny, M. E. (1987). The extent and function of parental attachment among $1^{\text {st }}$ Year College-Students. Journal of Youth and Adolescence, 16(1), 17-29. http://dx.doi.org/10.1007/ BF02141544

Kenny, M. (1990). College seniors' perceptions of parental attachments: The value and stability of family ties. Journal of College Student Development, 31, 39-46.

Kobak, R., \& Sceery, A. (1988). Attachment in late adolescence: Working models, affect regulation, and representations of self and others. Child Development, 59, 135-146. http://dx.doi. org/10.2307/1130395

Kallasmaa, T., \& Pulver, A. (2000). The structure and properties of the Estonian COPE Inventory. Personality and Individual Differences, 29, 881-894. http://dx.doi.org/10.1016/S01918869(99)00240-8

Lapsley, D. K., \& Edgerton, J. (2002). Separation-tndividualization, adult attachment style, and college adjustment. Journal of Counseling \& Development, 80, 484-492. http://dx.doi.org/10. 1002/j.1556-6678.2002.tb00215.x

Lazarus, R. S. (1993). Coping theory and research: Past, present, and future. Psychosomatic Medicine, 55, 234-247.

Lazarus, R. S., \& Folkman, S. (1984). Stress, appraisal and coping. New York, NY: Springer.

Lyne, K., \& Roger, D. (2000). A psychometric re-assessment of the COPE questionnaire. Personality and Individual Differences, 29, 321-335. http://dx.doi.org/10.1016/S0191-8869(99)00196-8

Little, T. D., Cunningham, W. A., Shahar, G., \& Widaman, K. F. (2002). To parcel or not to parcel: Exploring the question, weighing the merits. Structural Equation Modeling, 9, 151173. http://dx.doi.org/10.1207/S15328007SEM0902_1
Litman, J. A. (2006). The COPE inventory: Dimensionality and relationships with approach- and avoidance-motives and positive and negative traits. Personality and Individual Differences, 41, 273-284. http://dx.doi.org/10.1016/j.paid.2005.11.032

Lopez, F. G. (1996). Attachment-related predictors of constructive thinking among college students. Journal of Counseling \& Development, 75, 58-63. http://dx.doi.org/10.1002/j.15566676.1996.tb02315.x

Lopez, F. G., \& Brennan, K. A. (2000). Dynamic processes underlying adult attachment organization: Toward an attachment theoretical perspective on the healthy and effective self. Journal of Counseling Psychology, 47, 283-300. http://dx.doi.org/10.1037/0022-0167.47.3.283

Lopez, F. G., Maurício, A., Gormley, B., Simko, T., \& Berger, E. (2001). Adult attachment orientations and college student distress: The mediating role of problem coping styles. Journal of Counseling and Development, 79, 459-464. http://dx.doi.org/ 10.1002/j.1556-6676.2001.tb01993.x

Main, M. (1990). Cross-cultural studies of attachment organization: Recent studies, changing methodologies, and the concept of conditional strategies. Human Development, 33, 48-61. http://dx.doi.org/10.1159/000276502

Main, M. (1996). Introduction to the special section on attachment and psychopathology: 2. Overview of the field of attachment. Journal of Consulting and Clinical Psychology, 64, 237-243. http://dx.doi.org/10.1037/0022-006X.64.2.237

Matos, P. M., \& Costa, M. E. (2004, May). Assessing attachment representations in adolescence: the father/mother attachment questionnaire. Poster presented at IX Conference of the European Association for Research on Adolescence, Porto, Portugal.

McCarthy, C. J., Moller, N. P., \& Fouladi, R. T. (2001). Continued attachment to parents: Its relationship to affect regulation and perceived stress among college students. Measurement \& Evaluation in Counseling \& Development, 33, 198-213.

Mikulincer, M., \& Florian, V. (1998). The relationship between adult attachment styles and emotional and cognitive reactions to stressful events. In J. A Simpson \& W. S. Rholes. (Eds.), Attachment theory and close relationships (pp. 143-165). New York, NY: Guilford Press.

Mikulincer, M., Shaver, P. R., \& Pereg, D. (2003). Attachment theory and affect regulation: The dynamics, development, and cognitive consequences of attachment-related strategies. Motivation and Emotion, 27, 77-102. http://dx.doi.org/10. 1023/A:1024515519160

Moos, R. H., \& Moos, B. S. (1986). Family Environment Scale Manual. Palo Alto, CA: Consulting Psychologists Press.

Noom, J. M., Decovic, M., \& Meeus, W. H. J. (1999). Autonomy, attachment and psychosocial adjustment during adolescence: A double-edged sword?. Journal of Adolescence, 22, 771783. http://dx.doi.org/10.1006/jado.1999.0269

Ognibene, T. C., \& Collins, N. L. (1998). Adult attachment styles, perceived social support and coping strategies. Journal of Social and Personal Relationships, 15, 323-345. http://dx.doi. org/10.1177/0265407598153002 
Parker, G., Tuppling, H., \& Brown, L. B. (1979). A parental bonding instrument. British Journal of Medical Psychology, 52, 1-10. http://dx.doi.org/10.1111/j.2044-8341.1979.tb02487.x

Rice, K. G., FitzGerald, P. D., Whaley, T. J., \& Gibbs, C. L. (1995). Cross-sectional and longitudinal examination of attachment, separation-individuation, and, college student adjustment. Journal of Counseling and Development, 73, 463474. http://dx.doi.org/10.1002/j.1556-6676.1995.tb01781.x

Salovey, P., Mayer, M., Goldman, S. L., Turvey, C., \& Palfai, T. P. (1995). Emotional attention, clarity, and repair: Exploring emotional intelligence using the Trait Meta-Mood Scale. In J.W. Pennebaker (Ed.), Emotion, disclosure, and health (pp. 125154). Washington, DC: American Psychological Association.

Seiffge-Krenke, I., \& Beyers, W. (2005). Coping trajectories from adolescence to young adulthood: Links to attachment state of mind. Journal of Research on Adolescence, 15, 561-582. http://dx.doi.org/10.1111/j.1532-7795.2005.00111.x

Shaver, P. R., \& Mikulincer, M. (2002). Attachment-related psychodynamics. Attachment \& Human Development, 4, 133161. http://dx.doi.org/10.1080/14616730210154171

Shaver, P. R., \& Mikulincer, M. (2007). Adult attachment strategies and the regulation of emotion. In J. J. Gross (Ed.), Handbook of emotion regulation (pp. 446-465). New York, NY: The Guilford Press.

Sroufe, L. A. (2005). Attachment and development: A prospective, longitudinal study from birth to adulthood. Attachment and Human Development, 7, 349-367. http://dx.doi.org/10.1080/ 14616730500365928

Sroufe, L. A., \& Waters, E. (1977). Attachment as an organizational construct. Child Development, 48, 1184-1199. http://dx.doi.org/ $10.2307 / 1128475$

Steiger, J. H., Shapiro, A., \& Browne, M. W. (1985). On the multivariate asymptotic distribution of sequential chi-square statistics, Psychometrika, 50, 253-263. http://dx.doi.org/10. 1007/BF02294104

Thompson, R. A. (1994). Emotion regulation: A theme in search of definition. Monographs of the Society for Research in Child Development, 59, 25-52. http://dx.doi.org/10.2307/1166137

Treynor, W., Gonzalez, R., \& Nolen-Hoeksema, S. (2003). Rumination reconsidered: A psychometric analysis. Cognitive Therapy and Research, 27, 247-259. http://dx.doi.org/10.1023/ A:1023910315561

Vivona, M. (2000). Parental attachment styles of late adolescents: Qualities of attachment relationships and consequences for adjustment. Journal of Counseling Psychology, 47, 316-329. http://dx.doi.org/10.1037/0022-0167.47.3.316

Waters, E., Crowell, J., Elliot, M., Corcoran, D., \& Treboux, D. (2002). Bowlby's secure base theory and the social/personality psychology of attachment styles: Work(s) in progress. Attachment \& Human Development, 4, 230-242. http://dx.doi. org/10.1080/14616730210154216

Wei, M., Heppner, P. P., \& Mallinckrodt, B. (2003). Perceived coping as a mediator between attachment and psychological distress: A structural equation modeling approach. Journal of Counseling Psychology, 50, 438-447. http://dx.doi.org/10.1037/ 0022-0167.50.4.438

Wei, M., Voge,1 D. L., Tsun-Yao, Ku., \& Zakalik, R. A. (2005). Adult attachment, affect regulation, negative mood, and interpersonal problems: The mediating roles of emotional reactivity and emotional cutoff. Journal of Counseling Psychology, 52, 14-24. http://dx.doi.org/10.1037/0022-0167. 52.1.14

Received January 14, 2011

Revision received July 19, 2011 Accepted September 12, 2011 